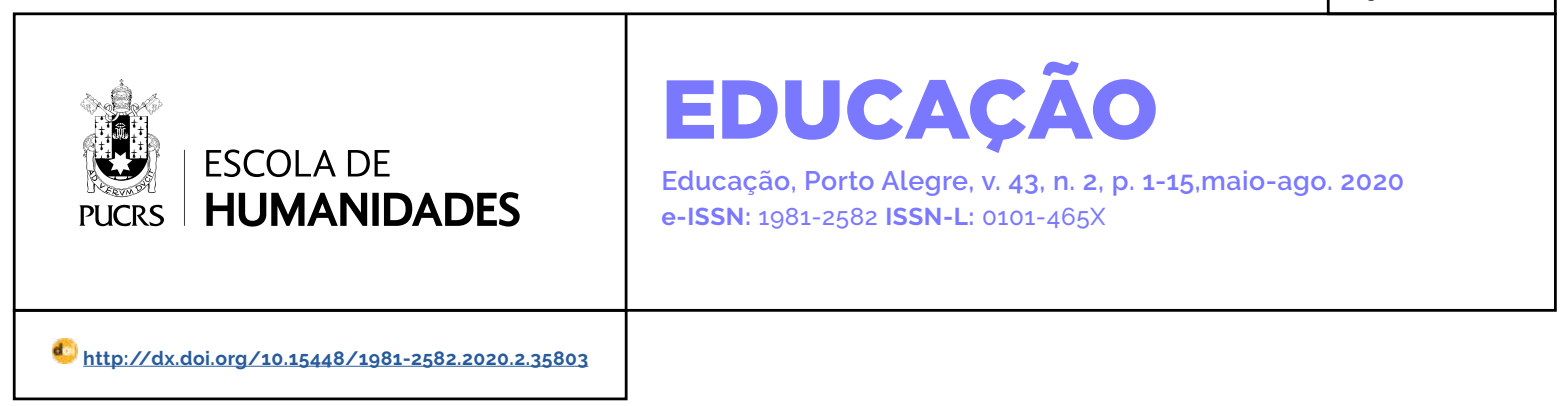

DOSSIÊ

\title{
Condição humana, mundo comum e educação
}

\author{
Condición humana, mundo común y educación \\ Human condition, common world and education
}

Jose Pedro Boufleuer ${ }^{1}$ orcid.org/0000-0003-3926-5164 jospebou@unijui.edu.br

\author{
Jenerton Arlan Schütz ${ }^{1}$ \\ orcid.org/0000-0002-3603-7097 \\ jenerton.xitz@hotmail.com
}

Recebido em: 26 set. 2019 . Aprovado em: 6 jun. 2020. Publicado em: 2 dez. . 2020.
Resumo: Nós, errantes, espécie aberta e inacabada, obrigada a se ver com a incerteza e a dramaticidade da condição humana, escolhemos e estabelecemos modelos de convivência sempre provisórios, passiveis de modificação e aperfeiçoamento. Pensar a educação das gerações vindouras exige um olhar para aquilo que temos em comum, ou seja, o mundo humano, fruto de nossas interações e criações. $O$ esforço do presente texto consiste em compreender o que compõe a nossa condição humana e, a partir dela, o que a educação escolar e a docência têm a contribuir para a construção de um mundo humano comum. Será na perspectiva teórica da filósofa Hannah Arendt, especialmente a partir de sua obra $A$ Condição Humana, que essas tematizações serão propostas. Tomar o mundo humano comum como base e orientação para educarmos os recém-chegados significa que alimentamos o desejo de que este mundo continue, dure, se eternize.

Palavras-chave: condição humana, educação escolar, crianças, tradição

Resumen: Nosotros, errantes, especie abierta e inconclusa, puesta a hacer frente a la incertidumbre y la dramaticidad de la condición humana, elegimos y establecemos modelos de convivencia siempre provisorios, sujetos a modificación y perfeccionamiento. Pensar en la educación de las generaciones futuras requiere una mirada a lo que tenemos en común, es decir, el mundo humano, el fruto de nuestras interacciones y creaciones. El esfuerzo de este texto es comprender qué constituye nuestra condición humana y, a partir de ella, qué la educación escolar y la docencia tienen a contribuir a la construcción de un mundo humano común. Será desde la perspectiva teórica de la filósofa Hannah Arendt, especialmente de su trabajo La condición humana, que se propondrán estas tematizaciones. Tomar el mundo humano común como base y orientación para educar a los recién llegados significa que alimentamos el deseo de que este mundo continúe, dure y se vuelva eterno.

Palabras clave: condición humana, educación escolar, niños, tradición

Abstract: We wanderers, open and unfinished species, forced to deal with the uncertainty and the dramatic nature of the human condition, have chosen and established models of coexistence always provisional, subject to modification and improvement. Thinking about the education of future generations requires a look at what we have in common, that is, the human world, the fruit of our interactions and creations. The aim of this text is to understand what makes up our human condition and, from it, what school education and teaching have to contribute to the construction of a common human world. It will be from the theoretical perspective of philosopher Hannah Arendt, especially from her work The Human Condition, that these thematizations will be proposed. Taking the ordinary human world as the basis and guidance for educating newcomers means that we nurture the desire for this world to continue, last, and become eternal. Keywords: human condition, schooling, children, tradition 
A nossa condição humana é marcada pela errância, fragilidade, incerteza, dramaticidade. Estamos perdidos na imensidão do cosmos. O que nos resta diante dessa perdição? O que caracteriza a nossa condição humana? Por que deveríamos educar as gerações vindouras, considerando este contexto caótico e, quem sabe, sem sentido algum? Dado esse quadro, o que nos permite, ainda, viver juntos? Teria a educação escolar algo a contribuir com esse cenário imprevisivel? Se sim, qual o lugar da escola e qual a função da docência em face da chegada dos novos a este mundo? Essas e outras questões orientam este escrito.

Nosso esforço consistirá em compreender o que compõe a nossa condição humana e, a partir dela, o que a educação escolar e a docência teriam a contribuir para a construção de um mundo humano comum. Um mundo que possibilita dar as boas-vindas para cada geração que nele adentrar. Assim, num primeiro momento, apresentaremos a concepção de condição humana a partir das teorizações de Hannah Arendt; e, num segundo momento, articularemos tal compreensão com a constituição da educação escolar, buscando tematizar e tensionar a necessidade da instituição escolar, além de pensar o que compõe a especificidade da docência nessa instituição.

Acreditamos que a articulação entre a condição humana, a escola e a docência se faz necessária para se pensar o mundo humano a partir das relações mediadas na intersubjetividade, encontrando ai as razões de se educar as novas gerações. Sem se ter uma compreensão daquilo que nos constitui como humanos, e o modo como construímos o nosso mundo, de nada servirá uma escola e um professor, uma vez que não se saberá ao certo as razões de se ter escolas e de educar as novas gerações, restando tão somente uma educação ao bel-prazer de cada professor/escola.

Por isso, o indicativo é o de que toda e qualquer educação tenha que iniciar pelo mundo humano, pelas nossas realizações simbólicas, decorrentes da nossa capacidade de transcender as determinações instintivas e biológicas. Afinal, o mundo humano é criação humana, pois foram os humanos, com as condições de cada tempo, que criaram determinados padrões e artifícios simbólicos. Por isso, podemos afirmar que apenas nós, humanos, temos mundo, justamente pela possibilidade que temos de criar um mundo, modificá-lo, ampliá-lo, manipulá-lo etc. Desse modo, a educação escolar tem a ver com o narrar ${ }^{2}$ às novas gerações os diferentes aspectos e dimensões que configuram o mundo humano. Nesse sentido, a escola se baseia na tradição, na conservação e transmissão da cultura, o que possibilitará a sua futura renovação por parte das crianças de hoje.

Não obstante, uma educação voltada às raízes do passado significa ir para onde nos tornamos propriamente humanos. Só assim nos tornamos iguais e, ao mesmo tempo, diferentes. ${ }^{3}$ É nesse movimento que podemos encontrar os tesouros e saber quais os seus valores. Eis a importância da escola e da docência.

\section{Do lugar nenhum ao mundo humano comum: a condição humana à luz do pensamento de Hannah Arendt}

Pensar a condição humana é uma exigência inadiável, principalmente após as experiências catastróficas da Primeira e Segunda Guerra Mundiais, ou, então, após Auschwitz, para refletir com Adorno (1995). Levar em consideração tais experiências e outras tantas de nosso tempo significa pensar o que estamos fazendo de/com nós, de/com os outros, do/com o mundo. Esse é o movimento empreendido por Hannah Arendt na obra A Condição Humana (2010). Trata-se de uma obra que se converte em uma fenomenologia das próprias atividades humanas fundamentais no âmbito da vita ativa: o trabalhar, o fabricar e o agir. Importa dizer que nessa obra o objetivo da autora

\footnotetext{
2 Consideramos que a transmissão cultural é constitutiva de todas as sociedades humanas. Transmitir, portanto, não tem a ver com simplesmente repetir, pois juntamente com a transmissão se coloca a possibilidade da renovação do mundo humano. Contudo, a renovação não ocorre logo após o recebimento da herança, pois ela só se efetivará na mediação e interação com os outros humanos, adultos e já educados. 3 Se não fossem iguais, os homens seriam incapazes de compreender-se entre si e aos seus ancestrais, ou de fazer planos para o futuro e prever as necessidades das gerações vindouras. Se não fossem diferentes, se cada ser humano não diferisse de todos os que existiram, existem ou virão a existir, os homens não precisariam do discurso ou da ação para se fazerem entender. Com simples sinais e sons, poderiam comunicar suas necessidades imediatas e idênticas. (Arendt, 2010, p. 188)
} 
não é o de apresentar respostas únicas e fechadas em si, uma vez que para os problemas e perplexidades de seu tempo (nosso tempo), não há uma única solução, mas acordos que devem ser estabelecidos entre os humanos na intersubjetividade pública das opiniões. Isso representa a capacidade humana de transcender a mera adaptação ao meio natural, como também, na interação com os outros humanos, a possibilidade de constituir (mesmo que provisoriamente) modelos de convivência, percepções, regramentos, valores, referências, caminhos, enfim, um mundo humano comum.

Se não somos feitos de "arame rígido", como lembra Tugendhat (2007, p. 188), então podemos colocar a nossa condição humana em questão, haja vista que temos infinitas possibilidades de constituir um mundo humano, resultantes da plasticidade humana. Se a não rigidez é a nossa condição, então podemos e necessitamos estabelecer interações mediadas com os outros seres humanos na perspectiva de que sejam minimamente razoáveis. Isso só é possivel porque, segundo Gadamer (2002, p. 173), "apenas aos homens foi dado ainda o lógos, para que se informem mutuamente sobre o que é útil ou prejudicial, o que é justo e injusto". Assim sendo, é na coletividade/pluralidade que se possibilita, por meio da linguagem, criar proposições que regulem e legitimem as interações e a convivência humana. É na linguagem, e a partir dela, que os homens podem pensar o comum. Só temos algo em comum porque possuimos linguagem. Nessa direção, pensar a condição humana significa, segundo Arendt, "pensar o que estamos fazendo" (2010, p. 6), o que consiste em exercitar-se no humano, para que o humano não se negue ao humano, para não esquecer que estamos vivos.

Antes de abordar a condição humana, Arendt (2010, p. 26) inicia a sua obra esclarecendo a expressão vita activa que, para ela, significa "a vida humana na medida em que se empenha ativamente em fazer algo". Com essa expressão a autora busca designar três atividades humanas que considera fundamentais: o trabalho, o fabricar e o agir. Cada uma delas corresponde a uma das condições básicas de existência do ser humano no mundo. Passamos a definir e aprofundar cada uma dessas três atividades que compõem a vita activa.

Na perspectiva de Arendt (2010), o trabalho corresponde ao processo biológico do corpo humano, cujo crescimento espontâneo e consequente declínio estão ligados às necessidades vitais satisfeitas pela atividade do trabalho. Além disso, a autora afirma que, para que se consiga sobreviver, a condição humana da vida depende do trabalho. Com isso, busca-se satisfazer determinadas necessidades, adentrando no ciclo da produção e do consumo.

Na modernidade, porém, esse ciclo se estende cada vez mais para outras dimensões, uma vez que não se consomem somente alimentos, mas também imagens e modelos de vida, pois os produtos são considerados parte da cultura. E mesmo que a produção e o consumo sejam incessantes, satisfazer as carências vitais, sendo elas biológicas ou não, sempre será uma exigência. Esse ser humano que está submetido às necessidades sempre urgentes e obrigado a trabalhar para atendê-las é denominado por Arendt (2010) de animal laborans. Por fim, a autora salienta que essa atividade (o trabalho) não pode ser comunicada, pois ela é um movimento singular, de privação do corpo em relação ao outro.

O ser humano, no entanto, não está somente preso ao processo vital. Por meio de outra atividade, o fabricar, o homem pode romper esse ciclo incessante de produção-consumo e estabelecer um mundo que o proteja do contínuo ciclo natural. Assim, o homem é capaz de fabricar artefatos que lhe dão estabilidade e lhe oferecem um lar que ele não possui por natureza. Desse modo, o homo faber supera o incessante ciclo temporal do animal laborans. Por meio da obra, o homem modifica o mundo e estabiliza a vida humana. Ele se torna artesão de um mundo que the é próprio. É por isso que a condição humana para o fabricar é o fato de estar no mundo, a mundanidade, ou seja,

representa a dimensão da existência humana demandante de um mundo artificial de coisas duráveis, cuja permanência instaura, em contraposição ao tempo cíclico da vida biológica, uma temporalidade linear na qual se podem reconhecer vidas individuais, e não apenas a vida da espécie. (Correia, 2010, p. XXVI) 
A atividade do fabricar, contudo, não é considerada antipolítica, pois, por mais que o homo faber se isole para fabricar alguma coisa, ele está ligado com o mundo tangivel das coisas que está a produzir, e é justamente essa artificialidade humana que, em última instância, une e separa o ser humano.

Além de trabalhar e fabricar, o homem também é capaz de agir. Essa atividade ocorre unicamente entre os homens, ou seja, "corresponde à condição humana da pluralidade, ao fato de que homens, e não o Homem, vivem na Terra e habitam o mundo" (Arendt, 2010, p. 8). ${ }^{4}$ Cada novo ser humano que chega ao mundo é singular, ou seja, com cada novo nascimento não começa apenas uma outra história de vida, mas uma totalmente nova, diferente de todas as que já a antecederam ou que ainda virão.

O novo sempre acontece em oposição à esmagadora possibilidades das leis estatísticas e à sua probabilidade que, para todos os fins práticos e cotidianos, equivale à certeza; assim, o novo sempre aparece na forma de milagre. O fato de o homem ser capaz de agir significa que se pode esperar dele o inesperado, [...] ele é capaz de realizar o infinitamente improvável. E isso, [...] só é possivel porque cada homem é único, de sorte que cada nascimento, vem ao mundo algo singularmente novo. Desse alguém que é único pode-se dizer verdadeiramente que antes dele não havia ninguém. (Arendt, 2010, pp. 222-223)

Desse modo, a singularidade é constantemente mostrada e reafirmada no espaço público, onde não se revela como é alguém, mas sim quem é esse alguém. A resposta para essa pergunta se dá a partir das palavras e também das ações que são espalhadas no mundo e que admitem o reconhecimento entre os indivíduos.

A identidade do homem ou de cada homem, portanto, só pode ser vista e reconhecida pelos outros. Assim, o nome de alguém nada revela sobre como é ou quem é essa pessoa, a não ser que um dia, em algum lugar, se possa ouvir as suas palavras ou assistir as suas ações. Do mesmo modo, poderíamos dizer que só temos mundo por causa das palavras constituídas pela mediação do outro na linguagem 5 . Logo, o humano e a linguagem nascem juntos.

Não obstante o fato de o humano estar entre outros singulares, ele é instigado a se relacionare se comunicar com os diferentes, estabelecendo assim um espaço de convivência. Nesse espaço, cada ser humano pode se revelar, apresentar, singularizar e distinguir. Destarte, "nenhuma atividade pode tornar-se excelente se o mundo não proporcionar um espaço adequado para o seu exercicio" (Arendt, 2010, p. 60). ${ }^{6}$ Com as suas ações, os homens podem (re)criar o espaço do aparecimento, o lugar da política e também das histórias humanas. Assim, se nos inserimos neste mundo humano vindos do lugar nenhum por meio do nascimento, é somente pela ação, pelas palavras e atos, que realizamos uma espécie de segundo nascimento, um aparecimento público. Importa destacar que a ação não é uma imposição advinda da necessidade, sobrevivência ou utilidade, mas está vinculada à finitude da existência e dos propósitos humanos, por um lado, e ao mesmo tempo, à capacidade humana de uma grandeza radiante, radicada na liberdade humana, que desafia a morte com a memória.

Nesse sentido, a ação, segundo Arendt (2010, p. 8), "é a única atividade que se exerce diretamente entre os homens sem a mediação das coisas ou da matéria". Diferentemente do trabalho, que busca satisfazer as necessidades vitais, e da atividade do fabricar, que visa um produto final, a ação não se reduz a uma função nem a um meio, mas tem em si mesma a sua finalidade. A ação deve vir sempre acompanhada do discurso, senão perde o seu caráter inovador, pois, "se a ação, como início, corresponde ao fato do nascimento, se é

\footnotetext{
4 Falamos: o leão quando é ameaçado reage matando... e não falamos: o homem quando é ameaçado....

5 Assumimos a perspectiva de que nada está "dado de vez", ou solidificado de "uma vez só", mas que tudo o que venha a ser propriamente humano sempre se dá pela linguagem, pela experiência intersubjetiva da linguagem, pois somente pela linguagem é possível chegar a conclusões razoáveis de convivência humana. Diferentemente, portanto, de uma perspectiva metafísica e/ou ontológica que pressupõe um mundo "já feito" e "dado de vez", restando ao humano conhecê-lo e manipulá-lo, ignorando a incerteza e dramaticidade que constitui a vida humana.

6 Lembramos que os regimes totalitários prezavam por extinguir todos e quaisquer possibilidades de espaços públicos, com isso destruiam, também, a singularidade de cada humano. Porém, podemos considerar que é impossivel eliminar a liberdade que está presente em cada novo nascimento do ser humano e, com essa, a possibilidade de constituir (preservar ou renovar) um mundo comum.
} 
a efetivação da condição humana da natalidade, o discurso corresponde ao fato da distinção e é a efetivação da condição humana da pluralidade, isto é, do viver como um ser distinto e único entre iguais" (Arendt, 2010, p. 223). Se assim não fosse, em lugar de homens que agem haveria robôs mecânicos a realizar coisas que seriam humanamente incompreensiveis (Arendt, 2010).

Arendt (2010), ao analisar especificamente a atividade da ação, alerta para o fato de que não obstante todos os aspectos da condição humana tenham alguma semelhança com a política, a pluralidade é especificamente a condição pela qual existe toda vida política. É fundamental compreender que a pluralidade não se dá pelo simples fato da junção de seres singulares, mas sim, pela relação que os seres singulares têm entre eles. A pluralidade, os objetos, as palavras e as ações se relacionam entre os indivíduos e passam a condicionar a sua identidade. É fato, porém, que a pluralidade permite enxergar que o homem não está sozinho, e que existem tantas opiniões sobre algo quanto pessoas que habitam o mundo, cada uma com a sua singularidade. É essa pluralidade e presença entre outros que permite a constituição de um mundo humano comum.

Importante destacar que Arendt (2010), além de apresentar as três atividades humanas fundamentais (o trabalho, a fabricação e a ação), que correspondem às três condições básicas de existência do ser humano no mundo, oferece mais duas condições nas quais os seres humanos existem: a natalidade e a mortalidade. Observa-se que das três atividades fundamentais, é a ação que tem a relação mais estreita com a condição humana da natalidade, pois o novo começo pode fazer o homem sentir-se no mundo humano, com a capacidade de fazer o imprevisivel, isto é, de agir. A autora alerta que, no sentido de estabelecer uma iniciativa, o elemento de ação é inerente a todas as atividades humanas e, portanto, de natalidade. Analogamente, "como a ação é a atividade política por excelência, a natalidade, e não a mortalidade, pode ser a categoria central do pensamento político, em contraposição ao pensamento metafísico" (Arendt, 2010, p. 10).

Ao adentrar no conceito de condição humana”, no entanto, Arendt (2010, p. 11) adverte que "a condição humana não é o mesmo que a natureza humana, e a soma total das atividades e capacidades humanas que correspondem à condição humana não constitui algo equivalente à natureza humana". Tal noção fica ainda mais clara quando Arendt (2010, pp. 18-19) afirma que:

É altamente improvável que nós, que podemos conhecer, determinar e definir a essência natural de todas as coisas que nos rodeiam e que não somos, venhamos a ser capazes de fazer o mesmo a nosso próprio respeito. ... Em outras palavras, se temos uma natureza ou essência, então certamente só um deus pode conhecê-la e defini-la; e a condição prévia é que ele possa falar de um 'quem' como se fosse um 'que'.

Nesse sentido, em que consistiria, então, a condição humana? Aguiar, com base em estudo sobre a categoria condição humana presente no pensamento de Hannah Arendt, assim se expressa:
A humanidade do homem não é algo que possamos garantir a partir de sua definição em determinada direção. Trata-se de um acon- tecimento que se manifesta nas suas ações, palavras, pensamentos e obras. Os homens não são coisas que possam ser definidos uma vez por todas. O ser-próprio de um homem, o seu quem, só se revela quando dele se contar a história, feitos e palavras. O quem é a pessoa, o homem compreendido como ser humano. É importante frisar isso para que não caiamos numa visão estética ou religiosa da dignidade humana, isto é, na concepção que a reduz às obras que os homens produzem ou a uma alma imortal. Dignidade humana só pode ser pensada em relação com a estatura do homem no mundo, a sua importância, o seu lugar e o seu valor, sem, todavia, em momento algum, significar isso uma caida na visão que aponta o homem como o fim último da criação, senhor da natureza e da sociedade. Essa concepção permite o distanciamento com qualquer forma de substancialismo e padrão, pois esse quem é narrativo e não teórico, se revela nos feitos e palavras e não na adequação comporta-

\footnotetext{
7 A concepção de condição humana não pode ser considerada como uma interpretação metafísica, como se as atividades que nela se realizam devessem se realizar de uma forma única e para todo o sempre. A condição humana tem a ver com a orfandade do humano diante do mundo, por isso a necessidade de o humano construir referenciais de objetividade (bússolas de orientação comum). Somente assim podemos abrir possibilidades novas de configuração do mundo humano comum, já que esse jamais está dado, mas necessita ser produzido, motivo que exige o entendimento intersubjetivo.
} 
mental a um padrão aprioristicamente dado. Para surgir, o quem necessita da liberdade como condição humana, cujo sentido não é o distanciamento de uma condição escrava, superada por uma condição soberana de autonomia absoluta, mas, principalmente, do amor mundi, da disposição de agir e se interessar por algo que não é, da ordem da posse e, sim, do mundo comum sobre o qual o homem não tem controle algum [grifo nosso]. (Arendt, 2006, pp. 55-56)

Não obstante, no entendimento de Dalcin (2007, p. 27), Arendt percebe a categoria humana no sentido do acontecimento, do como e não do quem, considerando que não está empenhada em investigar a essência que dota o homem de humanidade, mas conduz seu pensamento a fim de entender a condição humana sempre fundada no humano real, fenomênico, aquele cuja condição sine qua non de existência é

a própria vida, a natalidade e a mortalidade, a mundanidade, a pluralidade e o planeta Terra. Estas condições - enfatizemos: condições e não determinações absolutas - são as fundamentais para que o homem possa aparecer, estar, encenar sua vida no mundo e dele desaparecer. Embora não expliquem "o que" somos - apenas possibilita dar algumas respostas ao "quem somos" - "pela simples razão de que jamais nos condicionam de modo absoluto". (Arendt, 2010, p. 19)

Nessa direção, Arendt lembra que as condições da existência humana são:

a vida, a natalidade e a mortalidade, a mundanidade, a pluralidade e a Terra lembora nos ajude a compreender], jamais podem 'explicar' o que somos ou responder à pergunta sobre quem somos, pela simples razão de que jamais nos condicionam de modo absoluto. (Arendt, 2010, p. 13)

Do mesmo modo, para Arendt (2010, p. 11) "a objetividade do mundo... e a condição humana complementam-se uma à outra; por ser uma existência condicionada, a existência humana seria impossivel sem coisas,... [seria assim] um não mundo, se não fossem os condicionantes da existência humana". Ainda segundo a autora, a mudança mais radical que poderia ocorrer com a condição humana seria uma emigração dos homens da Terra para algum outro planeta. E, mesmo que o evento já não seja inteiramente impossivel, implicaria numa vida em condições totalmente diferentes das que lhe são oferecidas na Terra. O trabalho, o fabricar e o agir deixariam de ter o mesmo sentido.

Por isso, a condição humana ultrapassa a compreensão das condições nas quais a vida foi dada ao homem. Para todos os efeitos, o mundo humano é sempre um artifício, uma autoprodução e invenção humana, uma vez que só os humanos têm mundo. Assim,

os homens são seres condicionados: tudo aquilo com o qual eles entram em contato tornam-se imediatamente uma condição de sua existência. O mundo no qual transcorre a vita activa consiste em coisas produzidas pelas atividades humanas; mas constantemente, as coisas que devem sua existência exclusivamente aos homens também condicionam os seus atores humanos. Além das condições nas quais a vida é dada ao homem na Terra e, até certo ponto, a partir delas, os homens constantemente criam as suas próprias condições que. a despeito de sua variabilidade e sua origem humana, possuem a mesma força condicionante das coisas naturais. O que quer que toque a vida humana ou mantenha uma duradoura relação com ela, assume imediatamente o caráter de condição da existência humana. É por isto que os homens, independentemente do que façam, são sempre condicionados. Tudo o que espontaneamente adentra o mundo humano, ou para ele é trazido pelo esforço humano, torna-se parte da condição humana. (Arendt, 2010, pp. 10-11)

Para Dalcin (2007), a distinção entre os dois modos de vida (bios) - a vita activa e a vita contemplativa ${ }^{8}$ - era assim reconhecida na tradição filosófica e religiosa até meados da Era Moderna. A ideia tradicional do mundo grego compreendia a contemplação como a mais elevada das faculdades humanas, atividade de ordem superior em relação à vita activa. Essa percepção coincidiu com a descoberta dos filósofos que adotaram a contemplação como seu modo de vida, considerando-a superior à vida política do cidadão na polis. Arendt (2010) acredita que no transcurso da existência é possivel que um homem viva sem nunca ter se entregado à contemplação, porém, não é possivel que um homem permaneça em estado de contemplação durante toda a sua existência.

Com isso, é possivel compreender que a vita 
activa e a condição humana dependem da relação entre as três atividades: o trabalho, o fabricar e o agir. Portanto, é necessário ir além do "trabalho" que sustenta a vida do homem, passando pelo "fabricar" que ajuda a constituir a artificialidade do mundo, até chegar ao "agir" que insere o homem na esfera pública onde ele pode ter uma vida dedicada aos assuntos públicos. É nesse transcurso que estão fixadas as condições que o homem necessita para deixar de ser apenas um vivente e experimentar o que representa a sua existência humana. É isso que constitui o legado e o mundo humano comum, mundo este construido a partir das relações intersubjetivas produzidas pela ação, pluralidade, pensamento e linguagem.

Para Arendt (2017), neste mundo no qual adentramos e aparecemos vindos de lugar nenhum, e do qual desaparecemos em lugar nenhum, mundo que nos precede e a nós sobrevive, transcende a duração de nossa vida tanto no passado quanto no futuro, e acolhe os recém-chegados como forasteiros que, nesse mundo, encontram as potencialidades para a íntegra realização de suas atividades humanas. Por isso,

Nada e ninguém existe neste mundo sem a presença de um espectador. Em outras palavras, nada do que é, à medida que aparece, existe no singular; tudo o que é, é próprio para ser percebido por alguém. Não o Homem, mas os homens é que habitam este planeta. A pluralidade é a lei da Terra. (Arendt, 2017, p. 35)

Nessa direção, para a autora "o nascimento e a morte de seres humanos não são simples ocorrências naturais, mas referem-se a um mundo no qual aparecem e do qual partem individuos singulares" (Arendt, 2010, p. 119). Com isso, o mundo humano tem a ver com o artificio e com os assuntos que ocorrem entre os homens, enquanto a natureza e a Terra, apesar de influenciarem a condição de vida humana, subsistiriam sem a presença deste. Por isso, "sem um mundo no qual os homens nascem e do qual se vão com a morte, haveria apenas um imutável eterno retorno, a perenidade imortal da espécie humana como a de todas as outras espécies animais" (Arendt, 2010, p. 119). Eis o caráter aberto e inacabado do humano.
Para Bárcena (2001, p. 97) nós viemos ao mundo nus, como estranhos, e nossa estranheza nos mostra os outros como um acontecimento que, por mais previsivel que possa parecer, de algum modo comove, mobiliza. Dá-nos a pensar, porque o nascimento, como já assinalamos, é um acontecimento que, ao romper a continuidade de um tempo, incorpora no mundo já constituído uma certa lacuna, uma surpresa ou novidade de certo modo marcante.

Em sintese, na obra A Condição Humana (2010), Arendt reitera que o homem, para continuar a viver (após o nascimento) precisa se dar conta da vida e da sua reprodução. Do mesmo modo, precisa reconhecer e constituir um mundo que o proteja das intempéries da natureza, bem como constituir um espaço público comum que possibilita a interação política, linguisticamente mediada. Por isso, podemos afirmar que não há, nesse contexto, nenhuma receita prévia de como os homens devem prezar pela sua reprodução biológica, pelo cuidado com a Terra, com mundo e da esfera pública. Logo, para a autora, a condição humana não tem a ver com uma essência que determina todos os seres predicados por ela, pois não define um conteúdo, porém, tem a ver com as condições nas quais o ser humano pode viver e se realizar.

Portanto, diferentemente dos outros seres vivos, que já nascem sendo o que deveriam ser, o que hão de ser irremediavelmente, aconteça o que acontecer, nós humanos, nascemos para a humanidade (Savater, 2012). É por isso que nossa humanidade biológica necessita sempre de uma confirmação posterior, algo denominado por Arendt como um segundo nascimento (natalidade), no qual, por meio do nosso esforço e das relações que travamos com os outros humanos, confirmamos definitivamente o primeiro nascimento.

O homem é inserido em um mundo que já existe, e é a partir do nascimento que ele constitui o mundo, esse nascimento, biológico, é o primeiro aparecimento do homem ao mundo. Logo, a natalidade não corresponde ao nascimento, que é de fato a condição inaugural da natalidade. $\mathrm{O}$ nascimento corresponde a um acontecimento, ou seja, momento em que somos recebidos na 
Terra, enquanto a natalidade é a possibilidade/ capacidade que temos de constantemente nos atualizarmos, de fazermos o novo, de nos refazermos, o que só acontece por intermédio da ação no mundo. Dito de outro modo, "é preciso nascer humano, mas só chegamos a sê-lo plenamente quando os outros nos contagiam com sua humanidade deliberadamente e com nossa cumplicidade" (Savater, 2012, pp. 24-25). Nessa direção, o mundo no qual as novas gerações são introduzidas é um mundo velho, isto é, um mundo preexistente, povoado por outros seres humanos, construído pelos vivos e pelas gerações anteriores, e só é novo para os que acabaram de adentrar nele.

A partir disso poderiamos retornar às questões primeiras: por que devemos educar as gerações vindouras? Teria a instituição escolar alguma razão ou especificidade na constituição de um mundo humano comum? Essas e outras indagações motivam a nossa escrita sobre a educação escolar e sua articulação intrínseca com a condição humana aqui explorada. Pois, se há um mundo humano comum passivel de ser analisado, valorado, explorado, revisto, aperfeiçoado etc., então deve ser este, juntamente com suas construções simbólicas e linguagens públicas, que deve ser apresentado às novas gerações por meio da instituição escolar.

O mundo comum é aquilo que adentramos ao nascer e que deixamos para trás quando morremos. Transcende a duração de nossa vida, tanto no passado quanto no futuro: preexistia à nossa chegada e sobreviverá à nossa breve permanência. É isto o que temos em comum, não só com aqueles que vivem conosco, mas também com aqueles que aqui estiveram antes e aqueles que virão depois de nós. (Arendt, 2013, p. 65)

É se ocupando com aquilo que nos é comum que conseguiremos produzir objetividades sobre o nosso mundo ${ }^{9}$, além de fazer com que o nosso mundo seja digno de ser apresentado às novas gerações. Só assim poderemos alimentar as nossas esperanças de que este mundo humano comum continue e dure quando nós não estivermos mais aqui. É aquilo que nos é comum que constitui o legado plausivel de ser transmitido às novas gerações. Desse modo, temos a necessidade de uma aprendizagem que precisa ser incorporada pelos recém-chegados. Portanto, a educação escolar sempre tem a ver (ao menos deveria ter) com aprender os padrões, modelos de ser e de interagir, produzidos pelas gerações anteriores, a fim de que esses padrões e modelos possam, no futuro, serem aperfeiçoados e/ ou modificados, em virtude de nossa condição sempre aberta, inacabada e imprevisivel.

\section{A constituição da educação escolar e da docência: um passado para o futuro}

Proliferam nos tempos atuais as mais variadas críticas endereçadas à instituição escolar, que vão desde a acusação de doutrinação, alienação, disciplinarização de corpos, homogeneização, com disciplinas e temas artificiais, centralização nos saberes dos professores, com o que restaria pouco espaço para a autonomia, o protagonismo e o interesse dos alunos. Acusa-se a escola, ainda, de não proporcionar a devida preparação dos alunos para a vida real, de não flexibilizar a sua formação e de oferecer um espaço pouco atrativo e prazeroso para os alunos. Com base em tais acusações, não raras vezes, entra em cena pública a questão da necessidade de reformar radicalmente a instituição escolar. A lista de reformas é longa, conforme Masschelein e Simons (2017, p. 19) apontam:

\begin{abstract}
a escola deve se tornar mais centrada no aluno, se esforçar para desenvolver o talento, ser mais sensivel ao mercado de trabalho e ao ambiente social de forma a motivar e atender ao bem-estar dos alunos, oferecer educação baseada em evidência, o que é mais eficaz e pode contribuir para a igualdade de oportunidades de uma forma real, etc.
\end{abstract}

Poderiamos incluir nesta lista a necessidade de a escola se centrar no desenvolvimento de competências e habilidades, tal como propõe a reforma do Ensino Médio brasileiro, além da alternativa de os alunos escolherem o que seria "melhor" para o seu percurso formativo. Em

\footnotetext{
9 Referimo-nos aos valores, crenças, tradições, culturas, costumes, normas, competências, técnicas etc., que constituem o mundo humano.
} 
sintese, trata-se de um movimento que parte da perspectiva de que o sentido da instituição escolar é o de "otimizar o desempenho de aprendizagem (individual)" (Masschelein \& Simons, 2017, p. 19). Pensar desse modo a escola corresponde apenas a sua funcionalidade e não àquilo que seria próprio da instituição, ou seja, que faz a escola ser escola.

Contudo, tais acusações à escola contemporânea falham, justamente, por ignorar aquilo que constitui a quintessência desta instituição. Afinal, o que a escola faz e para que serve? Não seria óbvio afirmar que a escola foi inventada pela sociedade para inserir as crianças no mundo? Não seria evidente afirmar que a instituição escolar busca munir os alunos com conhecimentos, linguagens públicas e habilidades peculiares para encontrarem um lugar na sociedade? Não seria, simplesmente, na escola que se iniciam as crianças nos conhecimentos historicamente produzidos pela humanidade (tradição)? Então, o que faz uma escola ser uma escola e não outra coisa? Será que ela (a escola), realmente, merece ser preservada diante das inúmeras possibilidades que se colocam contemporaneamente para aprender? Essas e outras reflexões nos movem a pensar o que constitui a especificidade da educação escolar e da docência, levando em consideração a nossa condição humana.

Primeiramente, é importante lembrar da passagem kantiana de que "o homem é a única criatura que precisa ser educada. Por educação entende-se o cuidado de sua infância (a conservação, o trato), a disciplina e a instrução como a formação" (Kant, 1999, p. 11). Com isso podemos aferir que munir ou equipar os alunos com conhecimentos, introduzi-los nas linguagens públicas e nos saberes culturalmente produzidos pela humanidade é uma tarefa árdua, lenta e gradual, que exige esforço, dedicação e escolhas, tanto por quem está a munir como também por aquele que está sendo munido.

Nessa especificidade, Savater (2012, p. 141) considera que: "[o ensinar] transmite porque quer conservar; e quer conservar porque valoriza certos conhecimentos, certos comportamentos, certas habilidades e certos ideais" que não deveriam ser relegados ao esquecimento. Pois, conforme Arendt (2013), transmitir o legado consiste em legar uma herança e, por isso, os antecessores devem decidir o que e como entregar o seu legado para aqueles que chegarão. Essa herança não se compõe apenas por aspectos materiais, mas inclui saberes e conhecimentos, princípios e compreensões. A visão de discernir é um elo que liga uma geração à outra, algo que nós partilhamos com aqueles que viveram aqui neste mundo, mas em outro tempo. Poderíamos acrescentar: esse movimento apenas é possivel com base na disciplina, no respeito e na obediência. Somente assim os recém-chegados terão aportes e suportes para encontrarem o seu lugar e agirem no mundo humano.

Em relação a isso, Bueb (2008) reforça a ideia de que a autoridade do professor tem a ver com a espera de respeito, consideração, como também obediência por parte do aluno. A obediência corresponde a uma virtude reverenciada ou a uma virtude secundária, pois obtém o seu valor, primeiramente, por meio da intenção a qual serve. Com isso podemos afirmar que educação sem autoridade não é educação. Do mesmo modo, referindo-se à disciplina, Bueb (2008, p. 18) afirma que:

\begin{abstract}
A disciplina é a criança mal-amada da pedagogia, mas é o fundamento de toda a educação. A disciplina representa tudo o que as pessoas detestam: obrigação, subordinação, renúncia decretada, repressão de instintos, delimitação das vontades próprias.... A disciplina começa sempre com determinação alheia e deveria terminar em autodeterminação. A disciplina na educação apenas se legitima por meio do amor para com crianças e jovens.
\end{abstract}

Nesse sentido, a única disciplina que é válida em educação, a única com caráter estritamente pedagógico, é a que tem a ver com a atenção. Segundo Larrosa (2018, p. 132), "a escola deve disciplinar corpos e mentes, claro que sim, mas para que estejam e sejam atentos". A disciplina escolar, e o professor que a impõe, busca produzir mentes e corpos atentos, corpos e mentes estudiosos, corpos e mentes capazes de se submeter às exigências da matéria de estudo. Nesse caso, se o professor é exigente é porque a matéria de estudos requer essa exigência. Quando o professor 
exige a disciplina é em nome do estudo, do esforço, da determinação, e não em seu próprio nome. Podemos, ainda, citar Kant (1999, p. 25) para indicar que ser disciplinado na educação significa: "procurar impedir que a animalidade prejudique o caráter humano, tanto no indivíduo como na sociedade. Portanto, a disciplina consiste em domar a selvageria". Isso apenas é possivel e necessário aos humanos, pois estamos inclinados à liberdade, enquanto os animais, pelo contrário, não necessitam da disciplina, em virtude do seu instinto e pelo fato de não aprenderem de seus antepassados, pois suas condições já são definidas e dadas previamente. Dito de outro modo, "os animais cumprem o seu destino espontaneamente e sem saber. O homem, pelo contrário, é obrigado a tentar conseguir o seu fim; o que ele não pode fazer sem antes ter dele um conceito" (Kant, 1999, p. 18). Por isso, só o humano tem a necessidade de cuidados e formação.

É este contexto, de certo modo, que justifica a necessidade da instituição escolar, dada a condição de que a educação escolar é sempre aperfeiçoada por várias gerações. Contudo, e por este fato, importa dizer que os recém-chegados não necessitam partir da estaca zero, uma vez que já há gerações munidas de conhecimentos anteriores, herdados das gerações precedentes, permitindo, desse modo, a aprendizagem em perspectiva de continuidade. Motivo esse que leva Boufleuer e Fensterseifer (2010) a considerar a espécie humana como uma espécie pedagógica, uma espécie que sempre aprende com alguém anterior, com alguém que veio antes e está a mais tempo no mundo.

Consequentemente, para os autores,

Não há dialética pedagógica sem docência, ou melhor, sem antes alguém se constituir como anterioridade pedagógica. Anterioridade no sentido de ter aprendido antes a ponto de poder assumir a tarefa de mediar a inserção social e cultural de quem está chegando. À pedagogia sempre foi atribuido um sentido de "condução". E como alguém poderia conduzir a outros por sendas nunca antes andadas? (Boufleuer \& Fensterseifer, 2010, p. 261)

Nessa direção, aquele que insere as novas gerações no mundo das produções humanas - por meio da educação escolar - tem a necessidade de ter aprendido antes aquilo que se propõe a ensinar. É constituindo-se em anterioridade pedagógica que o professor torna digno todo o conteúdo e a matéria de estudos que apresenta a seus alunos. Ora, se a escola é o lugar onde os professores entregam o mundo aos que a ele chegam, inclui-se a isso a necessidade de o professor saber o que constitui o mundo humano e o que é digno de ser posto à apreciação ou à mesa de discussões a cada dia de aula.

Se compreendermos que o professor oferece um passado para o futuro, então podemos considerar que ele ocupa um lugar destacado na educação escolar, já que oferecer um passado é iniciar os novos (alunos) nas tradições humanas, tarefa, por sinal, nada fácil. Para Bárcena (2001, p. 192), o passado existe porque podemos narrar, porque podemos evocar e fazer presente o que já ocorreu, o que já aconteceu, e porque podemos estabelecer uma relação de receptividade e de escuta com quem tem o poder de nos transmitir uma experiência memorável, destinada a ser guardada na memória.

Para ampliar a compreensão, Peters (1979) afirma que a educação escolar tem a ver com iniciar os novos nas atividades, nos modos de conduta e de pensamento, que possuem regras intrínsecas referentes ao que é possivel para a ação, para o pensamento e para o sentimento, nos mais variados graus de competência e relevância. E acrescenta que "se os professores não estiverem convictos disso, deveriam arranjar outra ocupação" (Peters, 1979, p. 125).

Nessa iniciação ao mundo faz-se necessário um sentido de cumplicidade e de comprometimento com o que constitui o conteúdo da educação. Isso sugere que o professor, antes de iniciar uma aula, faça uma espécie de exame de consciência, perguntando-se: - Qual o significado para mim do assunto que me proponho abordar com meus alunos? Encontraria em mim motivos para atestar a importância de sua aprendizagem? Trata-se, aqui, do entendimento da docência como testemunho vivo da cultura a ser tematizada através dos currículos escolares, o que exige da parte do professor, por ocasião da preparação de uma aula, 
a verificação do grau de intimidade que possui com o conhecimento que pretende trabalhar com os alunos (Boufleuer, 2013, p. 406). Põe-se, nesse sentido, a necessidade de o professor "saber bem" aquilo que se propõe a ensinar, ou, em outros termos, estar atravessado e, de alguma forma, ter incorporado em seu modo de ser e interagir os saberes que se põe a transmitir.

De outra parte, se a escola necessita se abrir para o mundo, a fim de introduzir os novos nas obras públicas que a história nos lega, então ela deve se configurar como um lugar à parte. Um lugar que, segundo Arendt (2013), é intermediário ${ }^{10}$, isto é, entre a esfera pública e privada. Ademais, ser um lugar à parte tem a ver com ser um lugar de suspensão, ou seja, um lugar em que o tempo, as necessidades e as rotinas que ocupam a vida dos alunos podem ser deixadas para trás. Masschelein e Simons (2017, p. 32) entendem que suspender é "tornar algo inoperante, ou, em outras palavras, tirá-lo da produção, liberando-o e retirando-o de seu contexto normal. É um ato de desprivatização, de desapropriação". É por esse fato, também, que as escolas têm muros, portões e portas, que caracterizam a suspensão e a contenção do fluxo cotidiano, da rapidez diária. É por isso que escola não é um shopping. uma sala de café, um restaurante, um parque de diversões, ou qualquer outra coisa.

Impedir que o fluxo torrente da vida social constituido por prazeres, desejos e necessidades imediatas - afete a escola significa oportunizar, a cada um que nela adentra, um espaço e lugar de pensar e se afastar das preocupações diárias, de chegar a outra coisa que não seja apenas as suas próprias margens. Pois, "se tudo é abertura, nada é abertura, e cada um se encontra sozinho dentro da espiral de sua própria concha" (Mattéi, 2002, p. 209). Desse modo, é importante destacar que suspender não tem a ver com destruir. mas com desativar, interromper e descontinuar. Por esse motivo, a frase de Victor Hugo, "uma escola que se abre é uma prisão que se fecha", merece ser reformulada para "uma escola que não se fecha é uma prisão que se abre", pois é essa não abertura que possibilita aos novos alcançarem o pensamento e serem familiarizados, lentamente, com as linguagens públicas. É por isso que a escola é um lugar em que o presente, o imediato e instantâneo, devem ser suspensos. É por isso, também, que Arendt reserva à escola um lugar destacado, como sendo a "a instituição que interpomos entre o domínio privado do lar e o mundo com o fito de fazer com que seja possivel a transição de alguma forma, da familia para o mundo" (Arendt, 2013, p. 238).

São as tentativas de "suspender essa suspensão", isto é, de fazer com que a escola responde às demandas imediatas dos alunos e da sociedade, tornando-a funcional, que acentuam a crise na educação à medida que negam a sua especificidade. É exatamente ao abrir a escola, na tentativa de que ela revolva as questões da vida, ou que ensine a viver, que muitos professores já não sabem mais o que fazer em sala de aula. Então perguntam-se: afinal, por que devo ensinar? O que devo ensinar? E o que preciso ser para ensinar? Por sua vez, os pais se perguntam: por que as crianças devem ir à escola? Por óbvio, ao negar o que é próprio da escola entra em crise tudo o que a ela diz respeito.

São essas confusões que contemporaneamente trazem à baila críticas à educação escolar, considerando-a conservadora, elitista, capitalista etc. São julgamentos que partem de teorizações políticas, sociais ou econômicas, mas jamais filosóficas. São críticas que, segundo Kohan, Masschelein e Simons (2017), reduzem a educação a funções de outra ordem, geralmente ao campo da aplicação, identificando-a com outra coisa, mas incapazes de entender aquilo que é próprio da instituição escolar, o que faz de uma escola uma escola. Em virtude disso, é preciso defender a escola de tais criticas, pois defendê-la significa mostrar para que serve a escola, o que faz da escola uma escola e não outra coisa, entendendo que aquilo que ela propõe é indispensável para o

10 Em A crise na educação, Arendt (2013) entende que para dar às crianças os meios eficazes de sair da intimidade do lar e entrar no mundo público, é preciso que a escola se constitua em um espaço intermediário, entre o lar que a criança nasce e o mundo onde ela deverá adentrar. 
humano, para tornar-se humano, para constituir um mundo humano comum.

Portanto, a escola que aqui defendemos, levando em consideração a nossa condição humana, é uma escola que seja escola, um lugar de suspensão, de lentificação, de pensamento, de comparecimento, de cumplicidade, de disciplina, de autoridade, de dedicação, de atenção. Um lugar em que as coisas do mundo humano comum se convertam em matérias de estudo, em materialidade humana. Referimo-nos às coisas do mundo humano como tudo aquilo que merece ser preservado e apresentado, e não relegado ao esquecimento. É nisso que consiste um currículo escolar, isto é, em percepções e saberes do mundo humano dignos de serem apresentados às gerações que chegam a esse mundo.

Nesse sentido, podemos afirmar que a escola não é aquilo que se pensa contemporaneamente a partir das reformas em pauta, já que não é um lugar para a formação de competências e habilidades, segundo e seguindo uma suposta funcionalidade social. Por isso não é o caso de substituir os conteúdos (rígidos, duradouros, lentos, exigentes) por competências (flexiveis, mutáveis, sempre suscetiveis de treinamento e retreinamento). É preciso desconstruir esse discurso antiescolar/educativo e anti-institucional, desvendando-lhe sua roupagem ideológica.

Destacamos que é da especificidade da instituição escolar potencializar a todos os alunos com os conhecimentos e saberes humanos, independentemente de seus antecedentes. É isso que faz da escola um lugar de aprendizagem especifico ${ }^{11}$, um lugar em que alunos podem, uma vez mais, se superar e renovar, futuramente, o mundo humano comum. Por isso, a docência consiste em dar a ver, exatamente porque os saberes introduzem uma visibilidade do mundo humano e dos seres que o habitam, visibilidade essa que tem como característica fundamental poder ser objeto de transmissão discursiva.

Ademais, se a nossa condição humana é mar- cada pela abertura, inacabamento, indeterminação, imprevisibilidade, errância, criatividade, inventividade, pluralidade e incerteza, isso significa que somos uma espécie que precisa e se põe a aprender, que precisa ir à escola e precisa da escola, que necessita de professores e responsáveis, que precisa ser disciplinada, que necessita de interditos, que precisa conhecer e se familiarizar com o mundo, que precisa e não dispensa os outros humanos, que necessita da convivência plural. É nesse movimento de se constituir humano na intersubjetividade e de construir um mundo humano com e para os outros (mundo comum) que poderemos dar as boas-vindas às gerações vindouras, que sempre precisam de nós. Eis o motivo de Arendt afirmar que

\begin{abstract}
A educação é o ponto em que decidimos se amamos o mundo o bastante para assumirmos a responsabilidade por ele e salvá-lo da ruina que seria inevitável não fosse a renovação e a vinda dos novos e dos jovens. A educação é, também, onde decidimos se amamos as nossas crianças, o bastante para não expulsá-las de nosso mundo e abandoná-las a seus próprios recursos, e tampouco arrancar de suas mãos a oportunidade de empreender alguma coisa nova e imprevista para nós, preparando-as em vez disso com antecedência para a tarefa de renovar um mundo comum. (Arendt, 2013, p. 247)
\end{abstract}

É isso que esperamos da escola e de cada professor que está ou estará em sala de aula. É essa especificidade que garante nossa inserção no mundo humano comum e permite conhecer as obras que a história nos lega, obras e ações humanas, tradições e valores, culturas e costumes. Os fios que tecem o passado e o presente, tudo isso, configura uma herança que dá um mundo possivel de se habitar. É essa continuidade, em forma de memória, que permite a durabilidade do mundo humano comum. Por isso, a memória é considerada uma possibilidade de narrar e reconhecer a autoridade dos mortos, das vitimas da história, inclusive, para que Auschwitz não se repita. Ademais, sempre seremos aquilo que formos capazes de fazer com o nosso passado

\footnotetext{
11 Pode-se aprender assistindo televisão, mas a televisão não é uma escola; pode-se aprender no museu, mas o museu não é uma escola; pode-se aprender na internet, mas a internet não é uma escola; pode-se aprender com o grupo dos camaradas, mas o grupo dos camaradas não é uma escola.
} 
e com o que queremos legar aos novos, cientes da imprevisibilidade da ação futura.

\section{Considerações finais}

Pensar a condição humana consiste em um movimento complexo, exigente e ao mesmo tempo de suspensão. Suspende-se o pensamento que supõe que há um sentido previamente posto (dado de vez), anterior à experiência humana no mundo, anterior às relações intersubjetivas que são constituidas pela linguagem. Nesse sentido, enfrentamos a temática a partir do abandono de quaisquer referências que não estejam vinculadas à experiência linguística como fundante da condição humana, uma vez que as bússolas (direções) precisam ser construidas mutuamente, sempre a partir das percepções que compartilhamos com os outros.

Assim sendo, se a linguagem é fundante da condição humana, então temos mundo porque temos linguagem, logo, só nós (humanos) temos mundo. Desse modo, podemos considerar que a linguagem necessita do outro para se efetivar, pois é com os outros e entre os outros que nos tornamos sujeitos aprendentes. É na linguagem assumida na pluralidade que construímos referenciais de objetividade e razoabilidade plausíveis para que possamos viver juntos. E, nesse movimento, constituímos um mundo humano comum. Somente pela linguagem podemos pensar o comum, o razoável, o desejável. Toda e qualquer decisão, orientação e educação que se situaria fora da linguagem deve ser considerada perigosa, enganosa e não desejável.

Ademais, se possuimos um mundo humano comum que merece ser preservado e aperfeiçoado, que necessita continuar e durar, então ele pode ser considerado digno e merecedor de ser apresentado aos recém-chegados, para que estes possam se familiarizar com aquilo que nós humanos aqui realizamos em tempos outros. Por isso, é preciso que todos aqueles que se responsabilizam pelas novas gerações e a sua educação sejam capazes de compreender a história da humanidade desde os primórdios até a contemporaneidade, frisando tanto os exemplos solidários como também as opressões, domina- ções e barbáries que foram fruto do ser humano. É assim que cada recém-chegado poderá se compreender e reconhecer na humanidade à qual pertence. Em sintese, necessitamos de uma educação que permita pensar e compreender a nossa condição humana. Por isso, a educação escolar consiste em manter a intersubjetividade a que está sujeita a existência humana.

Para Arendt (2013), a forma como a educação escolar deve desempenhar a sua tarefa de responsabilidade para com o mundo é voltando o seu olhar para o passado, e não para o futuro, já que nele foi colocado o que existe entre os homens. O passado é que contém a história de todos nós, ou seja, as nossas identidades como seres pertencentes ao mundo humano comum. Educa-se para que as heranças e histórias humanas possam se manter vivas: é no passado que se encontra o significado e o sentido da humanidade e mundanidade.

Compreender a escola como um lugar que tem o compromisso de apresentar o mundo aos mais novos significa considerá-la como um lugar à parte, um lugar que rompe, desativa e tensiona os fluxos diários, que rompe com a pressa, com as necessidades imediatas e espontâneas, com o intuito de mostrar a cada aluno aquilo que vale a pena desejar. Por isso, as escolas têm portas e muros, os muros separam, mas também protegem as crianças, impossibilitam que as crianças vão para onde quiserem ir, que protegem as crianças da familia, do shopping, das fábricas, dos McDonald's etc.. Portanto, entrar na escola tem a ver com sair de outros espaços/lugares e dispositivos. Entrar na escola é dedicar o seu tempo (livre) para as matérias de estudo, para compreender e se familiarizar com as linguagens públicas.

É a possibilidade de se estar em apenas um lugar, com tempo livre para comparecer, se entregar e aprender, que faz da escola um lugar de entrega aos estudos, de iniciação nas heranças simbólicas. Iniciar os alunos nas obras que a história nos lega é um movimento que exige muito, seja por parte de quem entrega e testemunha, como por parte de quem recebe e estuda. Por isso a iniciação não consiste em algo momentâneo e rápido, mas re- 
quer lentificação, suspensão, tempo (livre), esforço, atenção, disciplina e determinação. É na escola que o mundo se transforma em matéria de estudo. É na escola que as mentes e corpos são disciplinados para que os alunos se tornem estudiosos. É na escola que podemos criar o bem comum.

Não obstante, para apresentar o mundo para as novas gerações é preciso que a docência se configure em uma relação de intimidade com o mundo humano - é isso que se espera, igualmente, de todos os adultos que são responsáveis pelas crianças e pelo mundo. A relação de intimidade sempre está sob o exame prévio daquilo que se propõe a ensinar, daquilo que se coloca sobre a mesa. É preciso que o professor saiba e consiga justificar os motivos da sua disciplina estar presente no currículo escolar. É preciso que ele saiba o porquê da sua disciplina poder vir a fazer alguma diferença na vida dos alunos. É esse contexto que passa a configurar a autoridade docente, pois é o lugar e a sua tarefa especifica que lhe conferem a autoridade. Se isso não for levado a sério, a escola e a docência estarão fadadas ao fracasso. Nessa direção, o recado de Savater (2012, p. 29) é consistente: "na dialética do aprendizado é tão crucial o que sabem aqueles que ensinam quanto o que ainda não sabem os que devem aprender".

Portanto, a única coisa que faz da escola uma escola e do professor um professor é o amor e a responsabilidade pelo mundo e pelas novas gerações. Que esse conselho seja lembrado a todos aqueles que pisam e/ou pisarão nas escolas e que se responsabilizam e/ou se responsabilizarão pelas nossas crianças.

\section{Referências}

Aguiar, O. A. (2006) A categoria condição humana em Hannah Arendt. In A. Correia (Org.), Hannah Arendt e a condição humana (pp. 35-74). Salvador: Quarteto.

Arendt, H. (2010). A condição humana (R. Raposo; Trad.; Revisão e apresentação de Adriano Correia:;11ª ed. rev.). Rio de Janeiro: Forense Universitária.

Arendt, H. (2013). Entre o passado e o futuro. (M. W. Barbosa, Trad.; $7^{a}$ ed.). São Paulo: Perspectiva.

Arendt, H. (2017). A vida do espirito: O pensar, o querer, o julgar. (C. A. R. de Almeida, Trad.; $6^{a}$ ed.). Rio de Janeiro: Civilização Brasileira.
Bárcena, F. (2001). La esfinge muda: El aprendizaje del dolor después de Auschwitz. Rubi (Barcelona): Anthropos; Guadalupe N.I. (México): Universidad Autónoma de Nuevo León.

Bueb, B. (2008). Elogio à disciplina: Um texto polêmico. Trad. L. Leipnitz. Porto Alegre: Artmed.

Boufleuer, J. P. (2013 Maio/Agosto) A profissão professor: Crise de profissão ou profissão em crise? Linhas Críticas, 19(39), 391-408. https://doi.org/10.26512/lc.v19i39.4149.

Boufleuer, J. P., \& Fensterseifer, P. E. (2010). A re-configuração da dialética pedagógica com vistas a uma formação emancipadora. Curriculo sem Fronteiras, 10(2), 259-267.

Correia, A. (2010). Apresentação à nova edição brasileira. In H. A. Arendt. A condição humana (R. Raposo, Trad.; A. Correia, Rev. e Apres.; $11^{a}$ ed.). Rio de Janeiro: Forense Universitária, XIII-XLIV.

Dalcin. A. (2007). As atividades humanas e a educação no pensamento de Hannah Arendt. Dissertação (Mestrado) - Unijuí. ljui/RS.

Foucault, M. (2006). A hermenêutica do sujeito (M. A. da Fonseca. Salma Tannus Muchail, Trad.; $2^{a}$ ed.). São Paulo: Martins Fontes.

Gadamer, H.-G. (2002). Verdade e método Il: Complementos e indice. Trad. M. S. C. Schuback. Petrópolis, RJ: Vozes: Bragança Paulista; SP: Editora Universitária São Francisco.

Kant, I. (1999). Sobre a pedagogia (F. C. Fontanella, Trad:; $2^{\mathrm{a}}$ ed.). Piracicaba: Editora Unimep.

Larrosa, J. (2017). Elogio da escola (F. Coelho, Trad.; $1^{a}$ ed.). Belo Horizonte: Autêntica Editora.

Larrosa, J., \& Rechia, K. (2018). P de professor. São Carlos: Pedro \& João Editores.

Masschelein J., \& Simons M. (2017). Em defesa da escola: Uma questão pública (C. Antunes, Trad.; $2^{a}$ ed.). Belo Horizonte: Autêntica Editora.

Mattéi, J. F. (2002). A barbárie interior: Ensaio sobre o i-mundo moderno. Trad. I. M. Loureiro. São Paulo: Editora UNESP.

Peters, R. S. (1979). Educação como iniciação. In R. D. Archambault, Educação e análise filosófica. Trad. C. E. Guimarães \& Maria da Conceição Guimarães (pp. 101130). São Paulo: Saraiva

Savater, F. (2012). O valor de educar. (M. Stahel, Trad.; $2^{a}$ ed.). São Paulo: Planeta.

Tugendhat, E. (2007). Antropologia como Filosofia Primeira. In A. Pommer, P. D. FRAGA, \& P. R. Schneider (Orgs.), Filosofia e critica: festschrift dos 50 anos do Curso de Filosofia da Unijuí. (pp. 183-199). Ijui: Editora Unijuí.

\section{Jose Pedro Boufleuer}

Doutor em Educação pela Universidade Federal do Rio Grande do Sul (UFRGS), em Porto Alegre, RS, Brasil; professor Adjunto da Universidade Regional do Noroeste do Estado do Rio Grande do Sul (UNIJUI), em ljuí, RS, Brasil. 


\section{Jenerton Arlan Schütz}

Doutorando em Educação nas Ciências pela Universidade Regional do Noroeste do Estado do Rio Grande do Sul (UNIJUI), em ljuí, RS, Brasil; professor da Rede Pública Municipal de ensino do municipio de Santo Ângelo, RS, Brasil.

\section{Endereço para correspondência}

José Pedro Boufleuer/ Jenerton Arlan Schütz

Universidade Regional do Noroeste do Estado do Rio Grande do Sul

Departamento de Humanidades e Educação (DHE)

Rua do Comércio, 3000

98700000

ljuí, RS, Brasil 